\title{
REVITALISASI PENDIDIKAN BAHASA ARAB BERBASIS PENDIDIKAN LIFE SKILL PADA JURUSAN PENDIDIKAN BAHASA ARAB DI IAIN TULUNGAGUNG DALAM MENGHADAPI MASYARAKAT EKONOMI ASEAN (MEA)
}

\author{
Oleh \\ Adi Marsono \\ Institut Agama Islam Pangeran Diponegoro Nganjuk \\ Adimarsono230176@gmail.com
}

\begin{abstract}
The background of this research is that the emergence of the revitalization of education become the talk very interesting and crucial entered the times of the ASEAN Economic Community (MEA) recently. Seeing the condition of a nation that increasingly worse with a variety of educational failure phenomena occurring generation of people. At the regional level (ASEAN), Arabic is the language of the second alternative communication after the Malay language. Since Arabic is the language of the religious culture of the Islamic community of Malay and Arabic language turns more dominant than in English. This is because the majority of the people of ASEAN are Muslims who think that the Arabic language is flexible, open and elastic in answering the challenges of globalization and cultural transformation. State Islamic Institute (IAIN) Tulungagung is one of the universities which have policies, matakuliah, environment and curriculum that supports the education of Arabic-based life skill education in the ASEAN Economic Community mengahadapi (MEA). The method used in this research are : the type of research is qualitative descriptive. Methods of data collection are observation, interview, documentation. Methods of data analysis are reduction, data display and then drawing conclusions / verification.The results of this research are : 1) the revitalization of the Arabic language education based life skills education at State Islamic Institute (IAIN) Tulungagung in the ASEAN Economic Community (MEA) is conducted by: a) To formulate vision and mission that suppor Competence Life Skills Arabic, b) Develop curriculum a greater emphasis on deepening the Arabic language skills competence, c) Establishing Bi'ah Lughawiyah Arabic language in Campus and
\end{abstract}


Ma'had, d) Create a special program of learning the Arabic language, e) Mastery learning strategies and Arabic language skills, f) Lecturer Professional and have optimum competence, g) Provide additional extra-based Life Skills, and h) To sharpen the practical and Delivers Native speakers. 2) The implications of life skill education to the Arabic language education at State Islamic Institute (IAIN) Tulungagung for facing the ASEAN Economic Community, the following: a) Linking the use of language in context, b) Lecturer more frequent use of the media, c) Institutions must make improvements in particular, d) Optimization Arabic Education management, and e) Overcoming the obstacles faced.

\section{Pendahuluan}

Revitalisasi pendidikan menjadi perbincangan yang sangat menarik dan krusial memasuki era Masyarakat ekonomi ASEAN (MEA) baru-baru ini. Melihat kondisi bangsa yang kian terpuruk dengan berbagai fenomena kegagalan pendidikan generasi bangsa yang terjadi. Sebagai contoh gagalnya pendidikan pada tingkat perguruan tinggi (PT) antara lain: ${ }^{1}$ Pertama, lemahnya lulusan perguruan tinggi Indonesia dalam persaingan untuk melakukan inovasi. Kedua, rendahnya kompetensi mahasiswa pada penguasaan matakuliah yang berbasis life skill. Ketiga, berdasarkan data BPS tahun 2016, tingkat pendidikan pekerja di Indonesia sekitar $65 \%$ didominasi oleh pekerja berpendidikan SMP ke bawah dan sekitar 25 $\%$ oleh pekerja berpendidikan menengah. Sedangkan lulusan perguruan tinggi kontribusinya kurang dari $10 \%$.

Presiden Joko Widodo (Jokowi) menegaskan bahwa kita tidak perlu takut dalam menghadapi Masyarakat Ekonomi ASEAN Jokowi mengatakan:

"Indonesia harus pandai memanfaatkan peluang dalam kebijakan yang akan efektif mulai 2016. Semuanya harus direbut. Itu semua adalah tantangan bagi kita. Mana yang tidak efisien, diefisienkan.

1 Roy Van Gobel, Lulusan Perguruan Tinggi Indonesia Lemah Bersaing, 29 Februari 2016, [Tersedia] https://hargo.co.id/berita/lulusanperguruan-tinggi-indonesia-lemah-bersaing.html, [Online] Senin, 11 November 2019 : 07.45 WIB 
Mana yang kita lemah kompetisi, kita harus perbaiki. Mana regulasi yang menghambat juga kita perbaiki. Di sebelah mana daya saing kita, di sisi rakyat yang kita kurang harus kita perbaiki. Pendidikan tinggi harus berbenah diri dan siap bersaing," ujar Jokowi saat ditemui di Kuala Lumpur Convention Center (KLCC) Malaysia, Minggu (22/11/2015). ${ }^{2}$

Sudah merupakan kewajiban pemerintah untuk merevitalisasi pola pendidikan yang berorientasi pada pengembangan life skill dan penanaman karakter sebagaimana disebutkan dalam UU Sisdiknas No. 20 tahun 2003 Bab VI tentang Jalur, Jenjang, dan Jenis Pendidikan bagian kesatu (Umum) pasal 15 yang menyatakan bahwa Jenis pendidikan mencakup pendidikan umum, kejuruan, akademik, profesi, vokasi, keagamaan, dan khusus. ${ }^{3}$ Dengan harapan, pelaksanaan revitalisasi pendidikan mampu melahirkan sumber daya manusia tangguh secara moral dan intelektual, sehingga pada akhirnya Indonesia dapat terus berdiri tegak sebagai bangsa bermartabat dan adi luhung pada tingkat regional maupun internasional.

Pada tingkat regional (ASEAN), bahasa Arab adalah bahasa komunikasi alternatif kedua setelah bahasa Melayu. Sebab bahasa Arab adalah bahasa kultur religius bagi masyarakat Islam Melayu dan ternyata bahasa Arab lebih dominan dari pada bahasa Inggris. Hal ini disebabkan karena mayoritas masyarakat ASEAN adalah muslim yang beranggapan bahwa bahasa Arab bersifat luwes, terbuka dan elastis dalam menjawab tantangan globalisasi dan transformasi budaya ${ }^{4}$.

${ }^{2}$ Ray Jordan, Jokowi : Tak Usah Takut Masuk Masyarakat Ekonomi ASEAN, 22 November 2015, [Tersedia] https://finance.detik.com/beritaekonomi-bisnis/d-3077356/jokowi-tak-usah-takut-masuk-masyarakat ekonomi-asean, [Online] Senin, 11 November 2019 : 08.45 WIB

${ }^{3}$ Elsam, UU Nomor 20 Tahun 2003 Tentang Sistem Pendidikan Nasional, $26 \quad$ November 2014, [Tersedia] https://referensi.elsam.or.id/2014/11/uu-nomor-20-tahun-2003-tentangsistem-pendidikan-nasional/, [Online] Senin, 11 November 2019 : 09.05 WIB Ahmad Sohandji, Manusia, Teknologi, Dan Pendidikan Islam Menuju Peradaban Baru, (Malang: Universitas Islam Negeri Maulana Malik Ibrahim Malang Press, 2015), hlm. 95-96 
Masa depan pendidikan bahasa Arab bergantung pada upaya Perguruan Tinggi dalam mengembangkan kurikulum, model, metode, strategi dan manajemen serta yang tak boleh dilupakan adalah penjaminan mutu pendidikan bahasa Arab harus dilakukan secara terus menerusdan komprehensif untuk seluruh komponen sistem pendidikan yaitu input, proses, output, dan outcomes ${ }^{5}$. Perguruan Tinggi juga harus mampu menyerap dana secara maksimal pengalokasian anggaran pendidikan minimal 20\% dari APBN dan APBD berdasarkan UU No. 20 Tahun 2003 Pasal 49 Ayat 1, agar anggaran pengembangan pendidikan dapat direalisasikan secara efektif, konsisten, transparan, dan akuntabel.

Berdasarkan hasil wawancara yang diperoleh oleh Penulis, IAIN Tulungagung telah berperan aktif dalam pergumulan Masyarakat Ekonomi ASEAN (MEA) antara lain: Pertama, Pencapaian MOU dan LOA antara IAIN Tulungagung dengan beberapa perguruan tinggi di Thailand, Brunei Darussalam dan Malaysia. Kedua, Penelitian Kolektif dan Studi Banding ke Malaysia, Singapura dan Thailand secara berturut-turut pada tahun 2012 hingga 2013. Ketiga, Pertukaran Mahasiswa Indonesia-Thailand yang dirintis semenjak tahun 2013 dan hingga saat ini masih berlangsung dengan baik.

Pemilihan IAIN Tulungagung sebagai subyek penelitian dikarenakan pertimbangan-pertimbangan sebagai berikut: Pertama, Sebagai Kampus rintisan Word Class University (WCU). Kedua, Berdasarkan berbagai keberhasilan dan prestasi yang telah diraih baik tingkat regional maupun Internasional. Ketiga, adanya kebijakan, matakuliah, lingkungan dan kurikulum yang mendukung pendidikan bahasa Arab berbasis pendidikan life skill dalam mengahadapi Masyarakat Ekonomi ASEAN (MEA).

IAIN Tulungagung sebagai perguruan tinggi keislaman negeri di bawah binaan Kementerian Agama telah menyelenggarakan

${ }^{5}$ Jusuf Amir Faeisal, Reorientasi Pendidikan Islam, (Jakarta: Gema Insani Press, 2015), hlm. 65 
program Pendidikan Bahasa Arab (PBA) semenjak 8 Januari 2002 hingga saat ini, telah memperoleh akreditasi jurusan dengan nilai $\mathrm{A}$. Akan tetapi masih menyisakan permasalahan pendidikan bahasa Arab antara lain:

1. Kompetensi Mahasiswa yang masih lemah terutama kompetensi terhadap matakuliah berbasis life skill, seperti: maharatul kalam (berbicara), maharatul kitabah (menulis), khitobah (berpidato), insya' (mengarang bebas), nadwah ilmiah (menullis karya ilmiah), dan matakuliah lainnya. Jumlah mahasiswa yang memiliki kompetensi rendah masih mencapai 53\% dari jumlah keseluruhan Mahasiswa Jurusan Pendidikan Bahasa Arab.

2. Motivasi belajar Mahasiswa yang masih kurang. Masih banyak dijumpai mahasiswa yang kurang disiplin dalam mentaati peraturan Jurusan PBA. Masih banyaknya mahasiswa yang terlambat datang pada saat menghadiri perkuliahan maupun terlambat dalam mengumpulkan tugas matakuliah.

3. Metode dan strategi mengajar Dosen yang kurang inovatif. Hal ini menyebabkan banyaknya mahasiswa yang mengantuk di kelas karena pembelajaran yang monoton dan tidak menarik. Sebagian dosen mengajar hanya menggunakan metode ceramah dan metode qawaid dan tarjamah.

4. Sarana dan prasarana yang kurang memadai. Hanya terdapat dua laboratorium bahasa dan dua laboratorium komputer untuk mahasiswa PBA. Belum memiliki perpustakaan khusus yang memadai bagi mahasiswa PBA dan jumlah kelas perkuliahan yang masih terbatas.

5. Kebijakan Rektorat dan Dekanat yang kurang mendukung program-program Jurusan Pendidikan Bahasa Arab, terutama dari segi pembinaan dan pendanaan kegiatan-kegitan ektrakulikuler yang sangat mendukung peningkatan kompetensi mahasiswa pada matakuliah yang berbasis life skill seperti: program muaskar lughah (Arabic camp), usbu'ul lughah (Arabic week), pendelegasian mahasiswa PBA pada lomba-lomba tingkat provinsi, nasional bahkan nasional yang masih jarang dilakukan karena minimnya pembinaan dan dana. 
Hakekat Revitalisasi itu sendiri menurut Winantyo adalah proses, cara, dan perbuatan menghidupkan kembali suatu hal yang sebelumnya kurang terberdaya. Sebenarnya revitalisasi berarti menjadikan sesuatu atau perbuatan menjadi vital. Sedangkan kata vital mempunyai arti sangat penting atau perlu sekali. Dia menyebutkan, ke depan Indonesia lebih banyak membutuhkan sarjana dengan kemampuan teknik (life skill) yang memadai. Sayangnya sebagian besar pendidikan tinggi saat ini menghasilkan sarjana non teknik. Kondisi tersebut dipandang tidak ideal. Orientasi pendidikan tinggi di Indonesia perlu ditata kembali. Di Indonesia diduga sekitar 75-85\% lulusan perguruan tinggi berasal dari bidang non teknik. Hal yang sebaliknya terjadi di Korea Selatan, dengan lulusan sarjana sebagian besar di bidang teknik (life skill). ${ }^{6}$

Berpijak pada permasalahan di atas, Penulis berpendapat bahwa perlu adanya revitalisasi pendidikan bahasa Arab berbasis pendidikan life skill pada jurusan Pendidikan Bahasa Araab (PBA) di IAIN Tulungagung dalam menghadapi Masyarakat Ekonomi ASEAN (MEA). Sebab semenjak Desember 2015 pasar bebas kawasan Asia Tenggara akan di buka, kerjasama ini bertujuan agar terciptanya aliran bebas barang, jasa, dan tenaga kerja terlatih, terutama bahasa Arab yang menjadi alat komunikasi resmi dunia yang menjembatani negaranegara yang tergabung dalam ASEAN. Indonesia merupakan anggota dari organisasi geo-politik ASEAN yang sangat aktif. Sebagai salah satu anggota maka Indonesia berkewajiban untuk mentaati semua kebijakan yang telah disepakati yaitu untuk membebaskan semua aliran barang, jasa, dan tenaga kerja terlatih.

Pendidikan Life Skill adalah Pendidikan kecakapan hidup yaitu pendidikan yang memberi bekal dasar dan latihan yang dilakukan secara benar kepada peserta didik tentang nilai-nilai kehidupan sehari-hari agar yang bersangkutan mampu, sanggup, dan terampil menjalankan kehidupannya yaitu dapat menjaga

${ }^{6} \mathrm{R}$. Winantyo, dkk. Masyarakat Ekonomi Asean (MEA) 2015 Memperkuat Sinergi ASEAN di Tengah Kompetisi Global, (Jakarta: PT. Elex Media Komputindo, 2008), hlm. 5 
kelangsungan hidup dan perkembangannya dimasa yang akan datang. Karena kecakapan hidup merupakan kemampuan, kesanggupan, dan keterampilan yang diperlukan oleh seseorang untuk menjalankan kehidupan dengan nikmat dan bahagia, serta mampu memecahkan persoalan hidup dan kehidupan tanpa adanya tekanan. ${ }^{7}$

Masyarakat Ekonomi ASEAN (MEA) atau ASEAN Economic Community (AEC) merupakan konsep yang mulai digunakan dalam Declaration of ASEAN Concord II (Bali Concord II), Bali, Oktober 2003. ${ }^{8}$ MEA adalah salah satu pilar perwujudan ASEAN Vision, bersama-sama dengan ASEAN Economic Community (AEC atau Masyarakat Ekonomi ASEAN-ME), ASEAN Security Community (ASC), dan ASEAN Socio-cultural Community(ASCC). MEA adalah tujuan akhir ekonomi seperti di canangkan dalam ASEAN Vision 2020. Langakah untuk memperkuat kerangka kerja MEA bergulir di 2006 antara lain dengan formulasi blue Print atau cetak biru yang berisi target dan waktu penyampain MEA dengan jelas. Mempertimbangkan keuntungan dan kepentingan ASEAN untuk menghadapi daya saing global diputuskan untuk mempercepat pembentukan MEA dari 2020 menjadi 2015 (12 ASEAN Summit, Januari 2007). ${ }^{9}$

Melalui cetak biru (blue print) MEA, ASEAN telah melakukan berbagai pembangunan antara lain: pembangunan fasilitas perdagangan pada sektor informasi, teknologi, dan transportasi, pengimplementasisan ASEAN Single Window di masing-masing negara, harmonisasi kebijakan seperti adanya standar atau sertifikasi produk buatan ASEAN dengan MRA (Mutual Recognition Arrangement).

${ }^{7}$ Sumarno, Konsep Dasar Kebijakan Pendidikan Kecakapan Hidup (Life Skill), dalam Jurnal Dinamika Pendidikan, Vol. 9, No. 2, (Yogyakarta: Universitas Negeri Yogyakarta, 2002), hlm. 18

${ }^{8}$ Didiek Ahmad Supadie, Pengelolaan Sumber Daya Ekonomi Secara Islami Dalam Menghadapi Masyarakat Ekonomi ASEAN (MEA), (Semarang: Unissula Press, 2011), hlm. 34

${ }^{9}$ Ibid, hlm. 35 
Jurnal Dinamika Ekonomi Syariah

http://ejurnal.iaipd-nganjuk.ac.id/index.php/es

p-ISSN: 2654-3567

Ada 4 pilar terpenting untuk mewujudkan MEA 2015, 4 pilar tersebut yang telah disepakati oleh Para Pemimpin ASEAN adalah sebagai berikut: ${ }^{10}$

1. Pasar tunggal dan basis produksi

2. Kawasan ekonomi berdaya saing tinggi

3. Kawasan dengan pembangunan ekonomi yang setara dan

4. Kawasan yang terintegrasi penuh dengan ekonomi global.

Pencapaian MEA melalui penciptaan pasar tunggal dan kesatuan basis produksi, ditunjukan sebagai upaya perluasan melalui integrasi regional untuk mencapai skala ekonomis yang optimal. Langkah-langkah integrasi tersebut (proses liberalisasi dan penguatan internal ASEAN) menjadi strategi mencapai daya saing yang tangguh dan di sisi lain akan berkontribusi positif bagi masyarakat ASEAN secara keseluruhan maupun individual negara anggota. Pembentukan MEA juga menjadikan posisi ASEAN semakin kuat dalam menghadapi negoisasi internasional.

Sebagai pasar tunggal dan basis produksi ASEAN memiliki 5 elemen utama yaitu: ${ }^{11}$

1. Aliran bebas barang

2. Aliran bebas jasa

3. Aliran bebas investasi

4. Aliran modal yang lebih bebas

5. Aliran bebas tenaga kerja terampil.

Untuk mewujudkan kawasan ekonomi yang berdaya saing tinggi maka di perlukan beberapa elemen penunjang untuk mencapai itu semua, elemen-elemen tersebut yaitu: ${ }^{12}$

1. Kebijakan persaingan usaha,

2. Perlindungan konsumen

3. Hak atas kekayaan intelektual,

4. Pembangunan infrastruktur,

10 Vaitzhal Riva'I, dkk. Ekonomi Syari'ah, Konsep, Praktek dan Penguatan Kelembagaannya Dalam Menghadapi Masyarakat Ekonomi ASEAN (MEA), (Semarang: Pustaka Rizki Putra, 2013), hlm. 17

${ }^{11}$ Ibid, hlm. 18

${ }^{12}$ Ibid, hlm. 19 


\section{Perpajakan dan \\ 6. E-commerce.}

Tujuan utama persaingan usaha adalah memperkuat persaingan yang sehat sehingga dalam melakukan usaha akan menjaga mutu dan kualitas produk yang di pasarkan. Dan dalam mewujudkan persaingan usaha yang sehat, instusi dan perundang-undangan yang terkait dengan kebijakan persaingan usaha telah terbentuk dibeberapa negara ASEAN, yaitu Indonesia, Singapura, Thailand, dan Viet-Nam. ${ }^{13}$ Untuk mewujudkan kawasan dengan pembangunan ekonomi yang setara maka di perlukan pembangunan UKM dan prakrasa bagi intergrasi ASEAN dalam mewujudkan kesamarataan ekonominya.

Hal yang di perlukan dalam integrasi penuh dengan ekonomi global adalah dengan pendekataan koheren terhadap hubungan ekonomi eksternal, prastisipasi yang erus meningkat dalam jaminan suplai global. Itulah kiranya 4 pilar terpenting yang telah disepakati oleh pemimpin ASEAN dalam menjalankan MEA (Masyarakat Ekonomi ASEAN 2015).

Dalam menghadapi MEA maka di butuhkan sumber daya manusia yang terampil juga terdidik, karena sumber daya manusisa merupakan faktor produksi yang sangat penting. Sumber daya manusisa adalah penduduk yang siap mau dan mampu memberi sumbangan terhadap usaha pencapaian tujuan organisasi. Mahasiswa merupakan Sumber Daya Manusia (SDM) yang unggul dan harus mempunyai kelebihan dari pada yang lainnya.

Dari sebuah data jumlah mahasiswa Indonesia saat ini 4,8 juta orang, dan jika dihitung terhadap populasi penduduk berusisa 19-24 tahun, maka angka partisipasi kasar (APK) perguruan tinggi yaitu 18,4 $\%$, berarti ada lebih dari 81,6\% anak usia 19-24 tahun tidak mengalami kesempatan untuk mengenyam pendidikan di perguruan tinggi/kuliah.

Mahasiswa sudah seharusnya dapat berperan dan menjadi garda dalam pembangunan bangsa. Peran mahasiswa dalam

${ }^{13}$ Didiek Ahmad Supadie. Pengelolaan Sumber Daya Ekonomi Secara Islami Dalam Menghadapi Masyarakat Ekonomi ASEAN (MEA) ..., hlm. 37 
pembangunan bangsa yaitu : Pertama sebagai kontrol sosial, mahasiswa dapat menjadi kontrol bagi berjalannya pemerintahan. Baik dalam pembuatan kebijakan maupun peraturan yang dilakukan oleh pemerintah. Mahasiswa juga bisa sebagai penyalur aspirasi masyarakat kepada pemerintah. Kedua sebagai bagian dari perubahan, sebagai kaum intelektual peranan mahasiswa sangat dibutuhkan dan penting dalam perubahan bangsa. Mahasiswa dapat merealisasikan teori yang di pelajarinya di kampus, terhadap masalah yang terjadi di masyarakat. Mahasiswa juga harus berpikir kritis dalam menyelesaikan masalah yang ada di masyarakat dan memberikan solusi. Selain itu mahasiswa sebagai kaum intelektual adalah generasi penerus bangsa untuk meneruskan dan menggantikan generasi sebelumnya untuk melakukan perubahan bangsa ke arah yang lebih baik dan maju. Ketiga sebagai iron stock, yaitu mahasiswa sebagai penerus atau aset cadangan bangsa untuk melakukan perubahan. Selain itu mahasiswa adalah harapan bangsa untuk meneruskan perjuangan di masa depan.

Pendidikan

bahasa

Arab adalah pengajaran dan pembelajaran bahasa Arab sebagai bahasa kedua. Pendidikan bahasa Arab merupakan bagian dari pembelajaran linguistik terapan. Pendidikan bahasa Arab dapat diberikan sebagai salah satu mata pelajaran pada sekolah umum, madrasah hingga perguruan tinggi, atau melalui suatu sekolah bahasa khusus. Pendekatan yang digunakan untuk pendidikan bahasa antara lain adalah metode iktisab al-Lughah yaitu metode pemerolehan bahasa kedua bagi penutur asing. Terbagi menjadi empat, yaitu keterampilan mendengar, keterampilan berbicara, keterampilan membaca dan keterampilan menulis. ${ }^{14}$

\section{METODE PENELITIAN}

Metode penelitian yang digunakan dalam penelitian ini yaitu : jenis penelitian: deskriptif - kualitatif. Metode pengumpulan data :

14 Ahmad Fuad, Metode Pendidikan Bahasa Arab, (Bandung: Alfabeta, 2015), hlm. 55 
Observasi, wawancara mendalam, dokumentasi. Metode analisis data : reduksi, display data kemudian penarikan kesimpula /verifikasi. Adapun uji kebasahan datanya menggunakan beberapa cara antara lain : perpanjangan penelitian, ketekunan pengamatan, dan triangulasi (sumber, teori, dan waktu).

\section{Hasil Dan Pembahasan}

1. Revitalisasi Pendidikan Bahasa Arab Berbasis Pendidikan Life Skill Pada Jurusan Pendidikan Bahasa Arab (PBA) di IAIN Tulungagung Dalam Menghadapi Masyarakat Ekonomi ASEAN (MEA)

Adapun revitalisasi pendidikan bahasa Arab Berbasis Pendidikan life skill di IAIN Tulungagung dalam Menghadapi Masyarakat Ekonomi ASEAN dilaksanakan dengan cara berikut ini:

a. Merumuskan Visi dan Misi yang yang mendudukung Kompetensi Life Skills bahasa Arab

Upaya tersebut dimulai dengan merumuskan visi misi jurusan yang mendukung, menyusun kurikulum yang sesuai (memberi muatan yang cukup untuk bahan ajar yang menekankan pada life skill) dan menyiapkan SDM yang memadai (kompeten) yang memahami kurikulum dan mampu megimplementasikannya dalam proses pembelajaran. Kompetensi adalah seperangkat pengetahuan, keterampilan, dan perilaku yang dimiliki, dihayati, dikuasai, dan diwujudkan oleh tenaga pendidik dalam melaksanakan tugas profesionalnya. ${ }^{15}$ Tidak sampai disitu, upaya itu harus didukung oleh pihak menajemen kampus(dekanat), juga para dosen dan tentu mahasiswa.

b. Menyusun kurikulum yang lebih menekankan pada pendalaman kompetensi keterampilan berbahasa Arab, memberi wawasan yang benar tentang bahasa Arab dan

${ }^{15}$ Farida Sarimaya, Sertifikasi Guru Apa, Mengapa, dan Bagaimana, (Bandung: Rama Widjaya, 2008), hlm. 17 
kaitannya dengan dunia kerja, menanamkan 3 hal penting dalam belajar bahasa Arab.

Adapun strategi peningkatan life skill pada mahasiswa Pendidikan Bahasa Arab (PBA) di IAIN Tulungagung dalam menghadapi Masyarakat Ekonomi ASEAN (MEA) berikut ini:

1) Menyusun kurikulum yang lebih menekankan pada pendalaman kompetensi keterampilan berbahasa (how to use) bukan pengetahuan bahasa (how to learn).

2) Merancang program pembelajaran bahasa Arab yang dinamis, efektif dan efesien

3) Upayakan memberi wawasan yang benar tentang bahasa Arab dan kaitannya dengan dunia kerja

4) Menanamkan 3 hal penting dalam belajar bahasa Arab; 1) jangan malu, 2) sering latihan, 3) target seimbang (Istima', kalam, qiro'ah, kitabah).

5) Dosen hendaknya memperhatikan: 1) Bahan pengajaran yang lebih mudah diserap oleh mahasiswa, 2) Sumber belajar yang dapat lebih dimanfaatkan untuk kepentingan peningkatan keterampilan berbahasa, 3) membawa mahasiswa agar dapat menerapkan pengetahuan dan keterampilan yang dipelajarinya untuk memecahkan masalah yang ditemui di sekitarnya, 4) mendorong mahasiswa agar mengenal kondisi lingkungan sosial, budaya yang sedang berkembang.

6) Yang penting juga adalah masalah evaluasi. Setiap kegiatan, khususnya yang berkaitan erat dengan pembelajaran keterampilan adalah evaluasi. Sejauhmana daya serap dan kemampuan mahasiswa menggunakan bahasa dalam kegiatan akademik dan social mereka.

c. Membentuk Bi'ah Lughawiyah bahasa Arab di Kampus dan Ma'had

Dalam meningkatkan life skill terdapat beberapa langkah kongkrit antara lain: (a) membentuk bi'ah lughawiyah, minimal di dalam kelas, (b) mengkondisikan 
mahasiswa Pendidikan Bahhasa Arab (PBA) agar mengikuti program-program pendalaman bahasa yang diselengarakan pihak ma'had jami'ah.

d. Membuat program khusus pembelajaran bahasa Arab, membangun relasi yang hangat dengan mahasiswa, dan membiasakan penggunaan bahasa Arab di dalam dan di luar kelas

Terdapat beberapa langkah untuk meningkatkan life skill berbahasa Arab, yaitu: (1) Membuat program khusus pembelajaran bahasa Arab, (2) Membangun relasi yang hangat dengan mahasiswa agar mereka merasa dekat sehingga nyaman dan tidak takut mengungkapkan bahasa kepada dosennya atau teman sejawatnya, (3) Membiasakan penggunaan bahasa Arab di dalam dan di luar kelas".

e. Penguasaan strategi pembelajaran dan keterampilan berbahasa Arab.

Penguasaan strategi pembelajaran keterampilan berbahasa. Seperti dalam pembelajaran menyimak di atas sesuai dengan beberapa strategi yang disampaikan Radliyah berikut: ${ }^{16}$ (1) Ta'lim Muta'awin, strategi ini sangat berguna bagi dosen, khususnya untuk mengetahui cara yang paling efektif dan berdaya hasil bagi pemahaman mahasiswa. Dan secara umum, strategi ini memberi kesempatan kepada mahasiswa untuk saling berbagi hasil belajar dari materi yang sama dengan cara berbeda dengan membandingkan catatan hasil belajar. (2) Talkhis Magza, strategi ini dapat menguji kemampuan menyimak mahasiswa terhadap isi cerita. Jawaban mahasiswa dari pertanyaan yang diberikan dosen kemudian disintesiskan ke dalam satu kalimat singkat, padat, dan jelas sehingga dapat menumbuhkan proses berfikir kreatif kritis terhadap topic yang diberikan. (3) Istima' Mutabadil,

16 Radliyah Zaenuddin, Metodologi dan Strategi Alternatif Pembelajaran Bahasa Arab, (Yogyakarta: Pustaka Rihlah Grup, 2005), hlm. 54-61 
strategi ini dapat mengiringi mahasiswa untuk tetap konsentrasi dan terfokus pada materi perkuliahan yang sedang disampaikan. Ia berguna untuk membentuk kelompokkelompok yang bertanggung jawab pada tugas yang terkait dengan materi. Misalnya mahasiswa dibagi 3 kelompok setiap kelompok memiliki tugas yang berbeda yaitu sebagai penanya, penentang dan pendukung dari satu topik materi yang disampaikan oleh dosen. (4) Istima' al-Aghani, strategi ini membantu mahasiswa untuk selalu tanggap dengan cermat dan tepat dalam memahami dan memaknai syair dan dinyanyikan. (5) Istima' al-Ma'lumat au al-Akhbar, strategi ini berkonsentrasi pada mahasiswa akan terfokus untuk tetap utuh meskipun dalam rentang waktu yang cukup lama. Mahasiswa dapat menyimak dengan seksama sebuah informasi sambil mendalami keruntutan bahasanya dan tingkat kekomunikasiannya. (6) Istima' al-Musykilat, strategi ini digunakan untuk meningkatkan rasa empati mahasiswa pada sesamanya.

f. Dosen yang Profesional dan memiliki kompetensi yang optimal.

Seorang dosen yang professional harus memiliki kompetensi atau strategi yang optimal. Salah satunya adalah strategi pembelajaran kalam. Strategi pembelajaran kalam ini meliputi ${ }^{17}$ : (1) Khibrat Mutsirah, strategi ini digunakan untuk memotifasi mahasiswa agar dapat mengungkapkan pengalaman-pengalaman yang pernah dialaminya berkaitan dengan teks yang akan diajarkan dan untuk mengajak keterlibatan mahasiswa dalam melihat pengalaman mereka sejak awal perkuliahan. (2) Ta'bir al-Ara' al-Ra'isiyyah, strategi ini sangat penting untuk mengasah keberanian mahasiswa dalam mengungkapkan bahasa Arab secara spontanitas kreatif, meski pada awalnya perlu penekanan bagi mahasiswa untuk berani tampil, namun bila telah terbiasa ia

${ }^{17}$ Ibid, hlm. 64-70 
akan melahirkan iklim yang kondusif lagi menyenangkan, di mana mahasiswa mendapatkan kebebasan berekspresi melalui bahasa mereka sendiri. (3) Tamstiliyyah, strategi ini adalah sebuah aktifitas yang membutuhkan kemampuan mahasiswa dalam mengekspresikan dialek bahasa Arab fusha dengan fasih dan sesuai makhrajnya, di samping dalam mengeksplorasikan kemampuannya dalam bermain peran. (4) Ta'bir Mushawwar, Strategi ini bertujuan agar mahasiswa dapat menirukan alur cerita dosen dengan cepat. Melalui bantuan media gambar, mahasiswa dapat membahasakan materi ajar dari persepsi yang ia bisa tangkap dari uraian dosen melalui bahasanya sendiri. (5) Yal'ab Daur alMudarris, strategi ini sangat tepat untuk mendapatkan partisipasi langsung baik dari kelas ataupun dari individual mahasiswa. Strategi ini memberi kesempatan kepada setiap mahasiswa untuk dapat berperan sebagai guru bagi kawankawannya. (6) Jidal Fa'aal, tema kontroversial adalah media berharga yang dapat menyulut motivasi belajar dan kedalaman pemikiran mahasiswa dalam menghadirkan argumentasi penganut pendapatnya, meski mungkin bertentangan dengan keyakinannya.

g. Memberi tambahan ekstrakurikuler berbasis Life Skills.

Memberi tambahan ekstrakurikuler sperti bimbel, Ansyithoh masrohiyyah, al-khitobah al-mimbariyah, almimbar al-hurr dan lainya yang mendukung penguatan life skill". Kegiatan seperti ini sangat mendukung kurikulum inti kampus. Pada saat mahasiswa pakum di dalam kelas, bisa jadi mereka akan lebih bergairah ketika mengikuti kegiatan ekstra. Kegiatan yang bisa disebut juga hidden kurikulum ini akan lebih efektif jika diikuti dengan proses kontroling, evaluasi dan follow up.

h. Mempertajam praktikum dan Menghadirkan Native speaker.

Adapun strategi peningkatan life skill mahasiswa PBA dalam mempertajam praktikum atau berbicara dengan Native Speaker meliputi: (1) Perlu membentuk dua 
lingkungan bahasa: a) buatan, b) alami. Buatan bisa diciptakan dalam kelas, sedangkan alami di luar kelas dimana mahasiswa berbahasa Arab dengan penuh kesadaran. (2) Peningkatan keterampilan bahasa lewat program praktikum. Program ini dilakasankan bekerjasama dengan pihak ma'had jami'ah atau dilakukan pihak jurusan secara mandiri. (3) Lebih banyak menghadirkan native speaker yang dapat melatih istima' dan kalam mahasiswa dengan pemilihan tema sekitar pembelajaran bahasa Arab sehingga diskusi lebih interaktif. Dengan demikian mahasiswa dapat dua keuntungan: memperoleh keterampilan bahasa dan mendapatkan konsep yang bermanfaat untuk membangun teori kebahasaan.

\section{Implikasi Pendidikan Life Skill Terhadap Jurusan Pendidikan} Bahasa Arab di IAIN Tulungagung Dalam Menghadapi Masyarakat Ekonomi ASEAN (MEA)

Adapun implikasi pendidikan life skill terhadap jurusan Pendidikan Bahasa Arab di IAIN Tulungagung dalam menghadapi Masyarakat Ekonomi ASEAN (MEA),

a. Mengaitkan penggunaan bahasa dengan konteks; menyampaikan dan mencari informasi faktual, melakukan sosialisasi keseluruah civitas akademika

Terdapat beberapa prinsip yang perlu diperhatikan dalam membangun life skill dalam Pendidikan Bahasa Arab, meliputi: (1) selalu mengaitkan penggunaan bahasa dengan konteks, sehingga materi ajar memiliki koneksi dengan kehidupan sehari-hari, (2) menyampaikan dan mencari informasi factual, dan (3) melakukan sosialisasi keseluruh civitas akademika, khususnya warga Pendidikan Bahasa Arab (PBA). Sosialisasi tersebut bisa lewat kegiatan MABA, pekan ta'aruf, rapat, diskusi dan sebagainya.

b. Dosen lebih sering menggunakan media; memperjelas penyajian pesan atau materi ajar; menyampaikan materi ajar dengan antusias, menyenangkan; memberi motivasi di awal, tengah, akhir kegiatan pembelajaran. 
Dalam meningkatkan life skill mahasiswa, dosen diharuskan menggunakan beberapa langkah strategis meliputi: (1) seyogyanya pendidik lebih sering menggunakan media pembelajaran bahasa, baik media pandang (visual aids), media dengar (audio aids) dan media dengar-pandang (audio-visual aids), (2) memperjelas penyajian pesan agar tidak abstrak, (3) memperjelas materi ajar dengan antusias, menyenangkan sehingga dapat memperlancar dan meningkatkan proses dan hasil belajar, dan (4) memberi motivasi di awal, tengah, akhir kegiatan pembelajaran.

c. Institusi harus melakukan pembenahan secara khusus.

Institusi harus melakukan pembenahan kuhsusnya dalam beberapa hal meliputi: (1) pembelajaran bahasa harus diarahkan kepada pengembangan kompetensi berbahasa yang tawazun, seimbang. Dalam arti tidak selalu teori, namun juga penekanan pada praktek, (2) memberi wawasan kepada mahasiswa tentang konsep-konsep penggunaan bahasa yang benar, dan (3) berusaha keras agar pendidik mampu menciptakan suatu $b i$ 'ah, lingkungan yang dapat menjamin para mahasiswa dapat belajar dengan baik.

d. Optimalisasi Managemen Pendidikan Bahasa Arab.

Dalam era globalisasi seperti sekarang ini, hususnya dalam menghadapi era MEA peran serta lembaga pendidikan Islam sangat menentukan tingkat pekembangan pendidikan Islam. Oleh karena itu pengembangan kurikulum pendidikan Islam hususnya kurikulum Pendidikan Bahasa Arab (PBA) sangatlah memiliki arti yang sangat penting sebagai bekal dalam menghadapi tantangan zaman yang semakin lama semakin kompleks. Era globalisasi menuntut adanya perubahan paradigma dalam dunia pendidikan. Untuk melakukan hal tersebut, peranan manajemen pendidikan 
sangat signifikan untuk menciptakan lembaga-lembaga pendidikan bermutu. ${ }^{18}$

Manajemen adalah suatu kegiatan atau rangkaian kegiatan yang berupa proses pengelolaan usaha usaha kerjasama sekelompok manusia yang tergabung dalam organisasi pendidikan, untuk mencapai tujuan pendidikan yang telah ditetapkan sebelumnya, agar efektif dan efisien. ${ }^{19}$ Dalam hal ini, para pihak perguruan tinggi dalam hal ini jurusan Pendidikan Bahasa Arab (PBA) harus memahami dengan baik tentang manajemen dan selalu berupaya unuk mengadakan pengelolaan terhadap sistem pendidikan yang ada di dalamnya untuk mencapai hasil sebaik mungkin. Manajemen ini terkait erat dengan pengelolaan SDM dosen dan mahasiswa, proses pembelajaran sampai pada sarana atau sumber pembelajarannya.

e. Mengatasi kendala-kendala yang dihadapi.

Banyak kendalanya, diantaranya adalah: tersebarnya asumsi yang keliru tentang bahasa Arab. Yakni tumbuhnya anggapan bahwa pelajaran bahasa Arab adalah pelajaran sulit bahkan paling sulit dibandingkan dengan pelajaran lainnya; (2) kurangnya komitmen pendidik dan mahasiswa dalam peningkatan keterampilan berbahasa, (3) belum adanya system yang mendukung penciptaan bi'ah luhowiyah, (4) sebagian mereka menganggap bahwa mempelajari bahasa Arab tidak perspektif secara ekonomi, tidak bisa digunakan dalam dunia kerja, berbeda dengan bahasa asing lainnya yang digunakan diberbagai lapangan pekerjaan. Anggapan seperti ini sebenarnya tidak akan terjadi jika para penanggung jawab pendidikan mampu mengelola pembelajaran bahasa Arab sebaik mungkin dan dapat

${ }^{18}$ Syafaruddin, Manajemen Mutu Terpadu dalam Pendidikan: Konsep, Strategi, dan Apikasi, (Jakarta: Grasindo, 2002), hlm. 15

19 Suharsimi Arikunto dan Lia Yuliana, Manajemen Pendidikan, (Yogyakarta: Aditya Media dan FIP UNY, 2008), hlm. 3 
melahirkan out put yang bermutu sesuai dengan harapan para pengguna hasil pendidikan".

Sedangkan unsur-unsur pendidikan yang berbasis kecakapan hidup bila dikomparasikan dengan pendidikan bahsa Arabakan terpetakan sebagai berikut:

1) Kecakapan personal (personal skill), yang mencakup kecakapan mengenal diri yang terinci menjadi keimanan sebagai makhluk Tuhan Yang Maha Esa yang dituntut untuk mengabdi kepada-Nya dan Khalifah-Nya di muka bumi. Pengemban karakter, antara lain cinta kebenaran, tanggung jawab dan disiplin, saling menghargai dan membantu dan sebagainya sebagai manifestasi dari nilainilai ketuhanan (self awareness) dan kecakapan berfikir rasional (thinking skill); yang mencakup dari kecakapan menggali informasi yang dapat dikembangkan dengan mencari tahu persoalan-persoalan kehidupan. Kecakapan mengelola informasi dengan melalui potensi berfikir untuk menyelesaikan persoalan kehidupan dengan tepat. Keterampilan mengambil keputusan setelah melalui proses berfikir tersebut. Kecakap memecahkan masalah setelah mengetahui berbagai persoalan dan dicarikan solusinya melalui proses berfikir tersebut. Dari kecakapan berfikir rasional tersebut adalah merupakan pengembangan potensi akal yang telah dianugeri Allah kepada manusia. Keterampilan ini sejalan dengan firman Allah dalam kitab suci Al-Qur'an yang berbunyi: Musa berkata: Tuhan menguasai timur dan barat dan apa yang ada diatara keduanya: itulah Allah jika kamu mempergunakan akal. ${ }^{20}$ Dalam surat al-baqarah ayat 70 berbunyi: (apakah mereka akan mengikuti juga), walaupun nenek moyang mereka tidak menggunkan akalnya ( tidak mengetahui sesuatu apapun) dan tidak

20 Muhammad Chirzin, Glosari Al-Qur'an, (Yogyakarta: Lazuardi, 2003), hlm. 13 
mendapat petunjuk (alternatif lain).

2) Kecakapan Sosial (sosial skill). Yang dapat dirinci dalam kecakapan komunikasi dengan empati, dan kecakapan bekerjasama. Dimana kecakapan sosial tersebut merupakan manifestasi dari sikap khalifah dimuka bumi dengan kerangka hubungan manusia dengan manusia yang lainnya agar tercipta kehidupan yang harmonis.

3) Kecakapan Akademik (academic skill) atau kemampuan berfikir ilmiah yang mencakup antara lain; identifikasi variabel. Merumuskan hipotesis dan melaksanakan penelitian yang merupakan pengembangan dari sikap pedagogik.

4) Kecakapan Vokasional (vocational skill) yakni keterampilan yang dikaitkan dengan pekerjaan tertentu yang terdapat dalam lingkungan atau masyarakat, yang merupakan bekal untuk hidup didunia, karena bagaimana pun juga orientasi pendidikan bahsa Arabtidak hanya pada wilayah rohaniyah saja tetapi juga jasmaniah.

Namun ada beberapa hal yang perlu dikritisi dalam pendidikan bahasa Arabdalam kaitannya dengan pendidikan berbasis kecakapan hidup, yaitu pada proses pelaksanaan pendidikan bahsa Arabitu sendiri, yang tidak mencerminkan terhadap unsur-unsur kecakapan hidup, karena secara metodologi pendidikan bahsa Arabmasih terkesan konservatif, metodologi pendidikan bahsa Arabtidak kunjung berubah antara pra dan post era modernisme, metodologi pendidikan bahsa Arablebih menitikberatkan pada aspek korespeondesitekstual yang lebih menekankan pada hafalan teks-teks keagamaan yang sudah ada, sedangkan kemampuan dalam menganalisis, kemampuan mencari dan memecahkan suatu problem dari teks-teks keagamaan tersebut kurang teraktualisasikan dalam proses belajar mengajar. Selain itu, kurikulum yang diterapkan dalam pendidikan bahsa Arabyang dirancang di sekolah sebenarnya lebih menawarkan minimum kompetensi atau minimum informasi, sehingga pihak guru 
pendidikan agama Islam sering kali terpaku padanya, sehingga semangat untuk memperkaya kurikulum dengan pengalaman belajar yang bervariasi kurang tumbuh.

Dari berbagai persoalan pendidikan bahasa Arab tersebut, bisa dikatakan belum mampu mengantisipasi masa yang akan datang, artinya belum mampu menyiapkan uot put yang sesuai dengan permintaan pasar, kurang memiliki kemampuan bersaing secara kompetitif, dan out putnya hanya mengandalkan ijasah tanpa diimbangi dengan kecakapankecakapan hidup.

\section{Kesimpulan}

1. Revitalisasi pendidikan bahasa Arab berbasis pendidikan life skill pada jurusan Pendidikan Bahasa Arab (PBA) di IAIN Tulungagung dalam menghadapi Masyarakat Ekonomi ASEAN (MEA) dilaksanakan dengan cara: (a) merumuskan visi dan misi yang yang mendudukung kompetensi life skills bahasa Arab, menyusun kurikulum yang lebih menekankan pada pendalaman kompetensi keterampilan berbahasa Arab, memberi wawasan yang benar tentang bahasa Arab dan kaitannya dengan dunia kerja, serta menanamkan 3 hal penting dalam belajar bahasa Arab, (b) membentuk bi'ah lughawiyah bahasa Arab di Kampus dan Ma'had, (c) membuat program khusus pembelajaran bahasa Arab, membangun relasi yang hangat dengan mahasiswa, d) membiasakan penggunaan bahasa Arab di dalam dan di luar kelas, (e) penguasaan strategi pembelajaran dan keterampilan berbahasa Arab, (f) dosen yang profesional dan memiliki kompetensi yang optimal, (g) memberi tambahan ekstrakurikuler berbasis life skills, dan (g) mempertajam praktikum dan menghadirkan native speaker.

2. Implikasi pendidikan life skill pada jurusan Pendidikan Bahasa Arab (PBA) di IAIN Tulungagung dalam menghadapi Masyarakat Ekonomi ASEAN meliputi: (a) mengaitkan penggunaan bahasa dengan konteks, menyampaikan dan mencari informasi faktual, melakukan sosialisasi keseluruah civitas akademika, (b) dosen 
lebih sering menggunakan media, memperjelas penyajian pesan atau materi ajar, menyampaikan materi ajar dengan antusias, menyenangkan, memberi motivasi di awal, tengah, akhir kegiatan pembelajaran, (c) institusi harus melakukan pembenahan secara khusus, (d) optimalisasi managemen Pendidikan Bahasa Arab, dan (e) mengatasi kendala-kendala yang dihadapi.

\section{Daftar Pustaka}

Arikunto, Suharsimi dan Yuliana, Lia, 2008. Manajemen Pendidikan, Yogyakarta : Aditya Media dan FIP UNY.

Chirzin, Muhammad, 2003. Glosari Al-Qur'an, Yogjakarta : Lazuardi.

Efendy, Ahmad Fuad, 2015. Metode Pendidikan Bahasa Arab, Bandung : Alfabeta.

Elsam, UU Nomor 20 Tahun 2003 Tentang Sistem Pendidikan Nasional 26 November 2014, [Tersedia] https://referensi.elsam.or.id/2014/11/uu-nomor-20-tahun-2003tentang-sistem-pendidikan-nasional/, [Online] Senin, 11 November 2019 : 09.05 WIB

Faeisal, Jusuf Amir, 2015. Reorientasi Pendidikan Islam, Jakarta : Gema Insani Press.

Gobel, Roy Van, 2016. Opini : Lulusan Perguruan Tinggi Indonesia Lemah Bersaing, dalam Jawa Pos.

Jordan, Ray, 2018. Jokowi : Tak Usah Takut Masuk Masyarakat Ekonomi ASEAN, Berita Aktual. Laporan dari Kuala Lumpur, dalam www.detik.com

Ray Jordan, Jokowi : Tak Usah Takut Masuk Masyarakat Ekonomi ASEAN. 22 November 2015, [Tersedia] https://finance.detik.com/berita-ekonomi-bisnis/d3077356/jokowi-tak-usah-takut-masuk-masyarakat-ekonomiasean, [Online] Senin, 11 November 2019 : 08.45 WIB

Riva'i dkk. Vaitzhal, 2013. Ekonomi Syari'ah, Konsep, Praktek dan Penguatan Kelembagaannya Dalam Menghadapi Masyarakat Ekonomi ASEAN (MEA), Semarang : Pustaka Rizki Putra.

Roy Van Gobel, Lulusan Perguruan Tinggi Indonesia Lemah $\begin{array}{lllll}\text { Bersaing, } & 29 & \text { Februari } & \text { 2016, } & \text { [Tersedia] }\end{array}$ 
Jurnal Dinamika Ekonomi Syariah

http://ejurnal.iaipd-nganjuk.ac.id/index.php/es

p-ISSN: 2654-3567

https://hargo.co.id/berita/lulusan-perguruan-tinggi-indonesialemah-bersaing.html, [Online] Senin, 11 November 2019 : $07.45 \mathrm{WIB}$

Sarimaya, Farida, 2008. Sertifikasi Guru Apa, Mengapa dan Bagaimana, Bandung : Rama Widjaya.

Sisdiknas, UU, 2019. UU Sisdiknas Online : No. 20 tahun 2003 Bab

VI tentang Jalur, Jenjang, dan Jenis Pendidikan, dalam www.academia.edu

Sohandji, Ahmad, 2015. Manusia, Teknologi, Dan Pendidikan Islam

Menuju Peradaban Baru, Malang : Universitas Islam Negeri Maulana Malik Ibrahim Malang Press.

Sumarno, Konsep Dasar Kebijakan Pendidikan Kecakapan Hidup (Life Skill), dalam Jurnal Dinamika Pendidikan, Vol. 9, No. 2, (Yogyakarta: Universitas Negeri Yogyakarta, 2002), hlm. 18

Supadie, Didiek Ahmad, 2011. Pengelolaan Sumber Daya Ekonomi Secara Islami Dalam Menghadapi Masyarakat Ekonomi ASEAN (MEA), Semarang : Unissula Press.

Syafaruddin, 2002. Manajemen Mutu Terpadu dalam Pendidikan:

Konsep, Strategi, dan Apikasi, Jakarta: Grasindo.

Zaenuddin, Radliyah, 2005. Metodologi dan Strategi Alternatif Pembelajaran Bahasa Arab, Yogyakarta : Pustaka Rihlah Grup. 